\title{
Adverse cardiac events in children with Williams syndrome undergoing cardiovascular surgery: An analysis of the Society of Thoracic Surgeons Congenital Heart Surgery Database
}

\author{
Christoph P. Hornik, MD, MPH, ${ }^{\mathrm{a}, \mathrm{b}}$ Ronnie Thomas Collins II, MD, ${ }^{\mathrm{c}}$ Robert D. B. Jaquiss, MD, ${ }^{\mathrm{a}, \mathrm{b}}$ \\ Jeffrey P. Jacobs, MD, ${ }^{d, e, f}$ Marshall L. Jacobs, MD, ${ }^{\mathrm{g}}$ Sara K. Pasquali, MD, ${ }^{\mathrm{h}}$ \\ Amelia S. Wallace, BSPH, ${ }^{\mathrm{a}, \mathrm{b}}$ and Kevin D. Hill, MD, MS ${ }^{\mathrm{a}, \mathrm{b}}$
}

\section{ABSTRACT}

Objective: Patients with Williams syndrome (WS) undergoing cardiac surgery are at risk for major adverse cardiac events (MACE). Prevalence and risk factors for such events have not been well described. We sought to define frequency and risk of MACE in patients with WS using a multicenter clinical registry.

Methods: We identified cardiac operations performed in patients with WS using the Society of Thoracic Surgeons Congenital Heart Surgery Database (20002012). Operations were divided into 4 groups: isolated supravalvular aortic stenosis, complex left ventricular outflow tract (LVOT), isolated right ventricular outflow tract (RVOT), and combined LVOT/RVOT procedures. The proportion of patients with MACE (in-hospital mortality, cardiac arrest, or postoperative mechanical circulatory support) was described and the association with preoperative factors was examined.

Results: Of 447 index operations (87 centers), median (interquartile range) age and weight at surgery were 2.4 years (0.6-7.4 years) and $10.6 \mathrm{~kg}(6.5-21.5 \mathrm{~kg})$, respectively. Mortality occurred in 20 patients $(5 \%)$. MACE occurred in 41 patients $(9 \%)$, most commonly after combined LVOT/RVOT (18 out of $87 ; 21 \%$ ) and complex LVOT (12 out of 131; 9\%) procedures, but not after isolated RVOT procedures. Odds of MACE decreased with age (odds ratio [OR], 0.99; 95\% confidence interval [CI], 0.98-0.99), weight (OR, 0.97; 95\% CI, 0.93$0.99)$, but increased in the presence of any preoperative risk factor (OR, 2.08; $95 \% \mathrm{CI}, 1.06-4.00)$, and in procedures involving coronary artery repair (OR, 5.37; 95\% CI, 2.05-14.06).

Conclusions: In this multicenter analysis, MACE occurred in $9 \%$ of patients with WS undergoing cardiac surgery. Demographic and operative characteristics were associated with risk. Further study is needed to elucidate mechanisms of MACE in this high-risk population. (J Thorac Cardiovasc Surg 2015;149:1516-22)

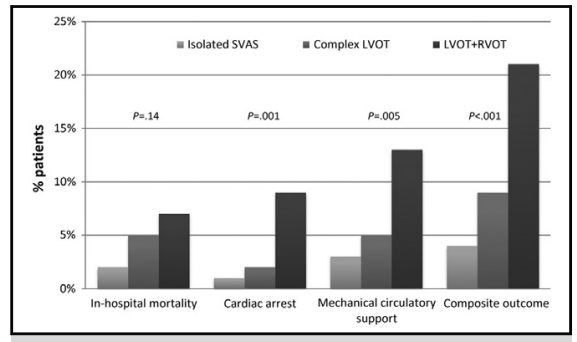

Major adverse cardiac events, sorted by cardiac surgical procedure group.

Central Message

Major adverse cardiac events are common in patients with Williams syndrome following cardiac surgery. Demographic and operative characteristics are associated with risk of those events in patients with Williams syndrome, a high-risk population.

\section{Perspective}

Patients with Williams syndrome undergoing cardiac surgery are at risk for major adverse cardiac events. Further, patients' demographic and operative characteristics are associated with risk for those events. Findings from this study, the largest to date examining outcomes in patients with Williams syndrome, will help predict the risk associated with specific cardiac operations to better counsel patients and families.

See Editorial Commentary page 1522.

\footnotetext{
From the Department of Pediatrics ${ }^{\mathrm{a}}$ and Duke Clinical Research Institute, ${ }^{\mathrm{b}}$ Duke University, Durham, NC; Division of Pediatric Cardiology, ${ }^{\mathrm{c}}$ University of Arkansas for Medical Sciences and Arkansas Children's Hospital, Little Rock, Ark; Andrews/ Daicoff Cardiovascular Program, ${ }^{\mathrm{d}}$ Johns Hopkins Children's Heart Surgery, St Petersburg, Fla; All Children's Hospital, ${ }^{\mathrm{e}}$ Tampa, Fla; Florida Hospital for Children, ${ }^{\mathrm{f}}$ Orlando, Fla; Department of Surgery, ${ }^{\mathrm{g}}$ Johns Hopkins University School of Medicine, Baltimore, Md; and Division of Pediatric Cardiology, ${ }^{\mathrm{h}}$ University of Michigan C.S. Mott Children's Hospital, Ann Arbor, Mich.

This research was supported by the National Center for Advancing Translational Sciences of the National Institutes of Health under award (grant\# UL1TR001117) (to $\mathrm{CPH}$ and $\mathrm{KDH}$ ) and by the National Heart, Lung, and Blood Institute under award (grant\# K08HL103631) (SKP). The content is solely the responsibility of the
}

authors and does not necessarily represent the official views of the National Institutes of Health, which had no role in study design; the collection, analysis, and interpretation of data; the writing of the report; or the decision to submit the manuscript for publication.

Received for publication Nov 21, 2014; revisions received Feb 2, 2015; accepted for publication Feb 9, 2015; available ahead of print March 17, 2015.

Address for reprints: Christoph P. Hornik, MD, MPH, Duke Clinical Research Institute, Duke University, PO Box 17969, Durham, NC 27715 (E-mail: christoph. hornik@dm.duke.edu). $0022-5223 / \$ 36.00$

Copyright (C) 2015 by The American Association for Thoracic Surgery http://dx.doi.org/10.1016/j.jtcvs.2015.02.016 


\section{Abbreviations and Acronyms \\ $\mathrm{CV}=$ cardiovascular \\ LVOT = left ventricular outflow tract \\ MACE = major adverse cardiovascular events \\ RVOT = right ventricular outflow tract \\ QTc = corrected QT interval \\ STS-CHS $=$ Society of Thoracic Surgeons \\ Congenital Heart Surgery Database \\ SVAS = supravalvular aortic stenosis \\ WS $\quad=$ Williams syndrome}

since 2000 at 120 centers in North America. It is estimated that the database currently represents approximately $93 \%$ of all US centers that perform congenital heart surgery and $>96 \%$ of all operations. ${ }^{10}$ Preoperative, operative, and outcomes data are collected on all patients undergoing pediatric and congenital heart surgery at participating centers. Coding for this database is accomplished by clinicians and ancillary support staff using the International Pediatric and Congenital Cardiac Code ${ }^{11}$ and is entered into the contemporary version of the STS-CHS data collection form. ${ }^{12}$ The Duke Clinical Research Institute serves as the data warehouse and analytic center for all of the STS national databases. Evaluation of data quality includes the intrinsic verification of data, along with a formal process of in-person site visits and data audits conducted by a panel of independent data quality personnel and pediatric cardiac surgeons at approximately $10 \%$ of participating institutions each year. ${ }^{10,13,14}$ This study was approved by the STS-CHS Database Access and Publications Committee and the Duke University Institutional Review Board, and was not considered human subjects research by the Duke University Institutional Review Board in accordance with the Common Rule (45 CFR 46.102(f)).

\section{Patient Population}

All index operations (first operation of a hospital admission) in the STSCHS database (2000-2012) among patients with a diagnosis of WS or a $7 q 11$ chromosomal abnormality were potentially eligible for inclusion ( $n=493$ operations from 89 centers). The index operation is defined by the STS-CHS database as the first CV operation (with or without cardiopulmonary bypass) of the hospitalization. Index operations for single ventricle heart defects $(\mathrm{n}=6)$ and those missing information on postoperative complications $(n=40)$ were excluded (Figure 1).

\section{Data Collection and Outcomes}

Data collection included demographic information, preoperative risk factors as defined in the STS-CHS database, diagnostic and operative variables, and outcomes data. ${ }^{15}$ Procedural cohorts were based on the primary and secondary components of the index operation and were defined as isolated SVAS intervention excluding all other interventions with the exception of patent ductus arteriosus closure, other LVOT procedures (including extended arch intervention), RVOT procedures, and combined LVOT/RVOT procedures.

The primary outcome of interest was the incidence of postoperative MACE, defined as postoperative death, cardiac arrest, or need for mechanical circulatory support. ${ }^{16}$ Other outcomes evaluated included arrhythmia, neurologic deficit persistent at discharge, unplanned reoperation, presence of an open sternum after surgery, need for prolonged mechanical ventilation, and the presence of any postoperative complications. The outcomes were chosen a priori given their clinical significance and their potential association with MACE.

\section{Analysis}

Population characteristics were described collectively and stratified by procedural group using standard summary statistics, including counts and percentages and median and interquartile ranges. Standard statistical tests, including $\chi^{2}$ tests of association and Wilcoxon rank sum tests were used to compare the distribution of categorical and continuous variables across the different procedural groups. The association between preoperative factors and MACE was also explored using univariate logistic regression Preoperative factors evaluated were chosen a priori based on their association with morbidity and mortality after congenital heart surgery in general (age, weight, previous cardiac surgery, and any preoperative risk factor), or their previously described potential implication in MACE in patients with WS (eg, arrhythmia or coronary procedures). Given the descriptive nature of this study and unavailability in the database of other important variables likely to affect WS outcomes, multivariable analysis

\section{METHODS}

\section{Data Source}

The Society of Thoracic Surgeons Congenital Heart Surgery (STSCHS) database was used for this study. As of January 2014, the database contains de-identified data on more than 292,000 surgeries conducted

Williams syndrome (WS) is a congenital, multisystem
disorder caused by a chromosome 7 microdeletion. ${ }^{1}$ Cardiovascular (CV) abnormalities occur in $80 \%$ of patients
with WS and are the leading cause of morbidity and mortality. ${ }^{2}$ The most common CV abnormalities are stenoses of medium and large arteries, including the left ventricular outflow tract (LVOT) and right ventricular outflow tract (RVOT)., ${ }^{2,3}$ These lesions often require Pation. peverall and across procedural horts, including those requiring coronary artery interventions or relief of left-sided obstructive lesions.

\footnotetext{
The Journal of Thoracic and Cardiovascular Surgery $\cdot$ Volume 149, Number 6
} 


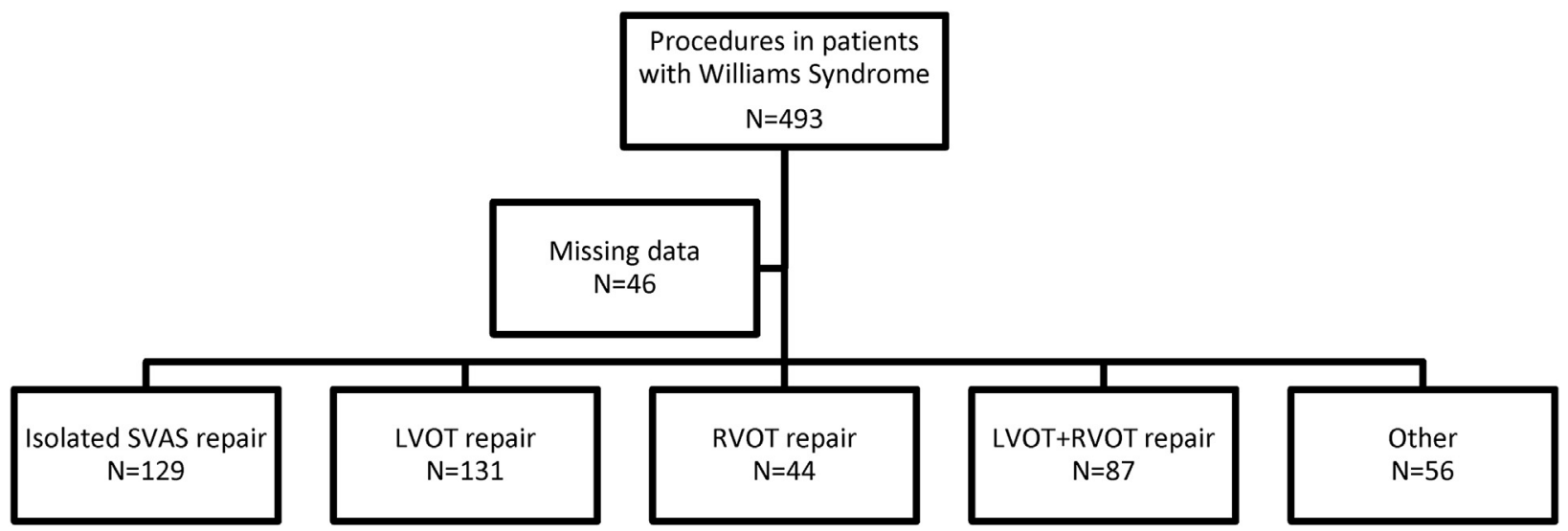

FIGURE 1. Flowchart of most common surgical procedure distributions in patients with Williams syndrome in the Society of Thoracic Surgeons Congenital Heart Surgery database. SVAS, Supravalvular aortic stenosis; LVOT, left ventricular outflow tract; RVOT, right ventricular outflow tract.

was not conducted. All analyses were done using SAS (version 9.3, SAS Institute, Inc, Cary, NC).

\section{RESULTS}

\section{Study Population Characteristics}

The cohort included 447 index CV operations at 87 surgical centers (Figure 1). The most common procedures and diagnoses are shown in Table E1. Overall, 77\% of procedures involved the LVOT (isolated SVAS, LVOT, or LVOT/ RVOT), whereas $30 \%$ involved the RVOT (RVOT or LVOT/RVOT). Combined LVOT/RVOT procedures were performed in $19 \%$ of the operations. Concomitant coronary artery procedures were rare (20 out of 447 [5\%]), occurring most frequently in the cohort undergoing combined LVOT/
RVOT procedures (10 out of 87 [11\%]). SVAS was the primary diagnosis in more than half of all procedures (247 out of 447 [55\%]). The majority of patients did not have a history of prior sternotomy (343 out of $447[77 \%]$ ).

\section{Operative Characteristics}

The median age and weight at surgery were 2.4 years (interquartile range, 0.6-7.4 years) and $10.5 \mathrm{~kg}$ (interquartile range, 6.5-21.5 years), respectively. Patients who underwent combined LVOT/RVOT procedures were younger at the time of surgery compared with those who underwent isolated SVAS repair or complex LVOT interventions $(P<.0001)$ (Table 1). STS-CHS-defined preoperative risk factors were present in 112 out of 447 total procedures

TABLE 1. Patient and operative characteristics

\begin{tabular}{|c|c|c|c|c|c|c|c|}
\hline Characteristic & $\begin{array}{c}\text { Overall } \\
(N=447)\end{array}$ & $\begin{array}{c}\text { Isolated SVAS } \\
(\mathbf{n}=\mathbf{1 2 9})\end{array}$ & $\begin{array}{c}\text { Complex LVOT } \\
\quad(n=131) \\
\end{array}$ & $\begin{array}{c}\text { Isolated RVOT } \\
\quad(n=44)\end{array}$ & $\begin{array}{c}\text { LVOT/RVOT } \\
\quad(\mathbf{n}=\mathbf{8 7})\end{array}$ & $\begin{array}{c}\text { Other } \\
(n=56)\end{array}$ & $\begin{array}{c}P \\
\text { value }\end{array}$ \\
\hline \multicolumn{8}{|l|}{ Demographic factors } \\
\hline Age at surgery (y) & $2.4(0.6-7.4)$ & $3.8(2.4-7.6)$ & $2.1(0.6-9.1)$ & $0.9(0.4-2.3)$ & $0.7(0.4-1.2)$ & $6.9(0.9-15.3)$ & $<.001$ \\
\hline Weight at surgery $(\mathrm{kg})$ & $10.6(6.5-21.5)$ & $13.6(10.2-24.1)$ & $11.3(6.4-25.8)$ & $7.6(5.2-10.4)$ & $6.9(5.4-9.3)$ & $19.2(7.9-42.3)$ & $<.001$ \\
\hline Male gender & $257(57.5)$ & $81(62.8)$ & $74(56.5)$ & $24(54.5)$ & $58(66.7)$ & $20(35.7)$ & .004 \\
\hline \multicolumn{8}{|l|}{ Preoperative factors } \\
\hline Any preoperative risk factors & $112(25.1)$ & $22(17.1)$ & $35(26.7)$ & $20(45.5)$ & $19(21.8)$ & $16(28.6)$ & .005 \\
\hline Mechanical circulatory support & $6(1.3)$ & $1(0.8)$ & $2(1.6)$ & $0(0)$ & $2(2.3)$ & $1(1.9)$ & .802 \\
\hline Mechanical ventilator support & $26(5.9)$ & $3(2.4)$ & $8(6.3)$ & $3(6.8)$ & $6(7.0)$ & $6(11.1)$ & .219 \\
\hline Neurologic deficit & $14(3.2)$ & $2(1.6)$ & $5(3.9)$ & $3(6.8)$ & $3(3.5)$ & $1(1.9)$ & .478 \\
\hline Prior sternotomy & & & & & & & $<.001$ \\
\hline 0 & $343(76.7)$ & $121(93.8)$ & $80(61.1)$ & $33(75.0)$ & $75(86.2)$ & $34(60.7)$ & \\
\hline 1 & $53(11.9)$ & $3(2.3)$ & $24(18.3)$ & $5(11.4)$ & $9(10.3)$ & $12(21.4)$ & \\
\hline$\geq 2$ & $38(8.5)$ & $1(0.8)$ & $22(16.8)$ & $5(11.4)$ & $3(3.4)$ & $7(12.5)$ & \\
\hline \multicolumn{8}{|l|}{ Operative factors } \\
\hline Cardiopulmonary bypass time (min) & $117(82-163)$ & $92(69-130)$ & $129(86-175)$ & $100(66-132)$ & $162(111-205)$ & $130(101-144)$ & $<.001$ \\
\hline Crossclamp time (min) & $63(42-95)$ & $56(44-79)$ & $64(41-91)$ & $38(0-68)$ & $96(55-121)$ & $75(39-109)$ & $<\mathbf{. 0 0 1}$ \\
\hline Concomitant coronary artery repair & $20(4.5)$ & $0(0)$ & $6(4.6)$ & $1(2.3)$ & $10(11.5)$ & $3(5.4)$ & .002 \\
\hline Subsequent coronary artery repair & $2(0.4)$ & $1(0.8)$ & $0(0)$ & $0(0)$ & $1(1.1)$ & $0(0)$ & 680 \\
\hline
\end{tabular}

Data are presented as $\mathrm{n}(\%)$ or median (interquartile range). Boldface type indicates statistical significance. SVAS, Supravalvular aortic stenosis; $L V O T$, left ventricular outflow tract; RVOT, right ventricular outflow tract. 
TABLE 2. Postoperative outcomes

\begin{tabular}{|c|c|c|c|c|c|c|c|}
\hline Outcome & $\begin{array}{c}\text { Overall } \\
(\mathrm{N}=447)\end{array}$ & $\begin{array}{c}\text { Isolated SVAS } \\
\quad(\mathbf{n}=\mathbf{1 2 9})\end{array}$ & $\begin{array}{l}\text { Complex LVOT } \\
\quad(\mathbf{n}=\mathbf{1 3 1})\end{array}$ & $\begin{array}{l}\text { Isolated RVOT } \\
\quad(n=44)\end{array}$ & $\begin{array}{l}\text { LVOT/RVOT } \\
\quad(\mathbf{n}=\mathbf{8 7})\end{array}$ & $\begin{array}{c}\text { Other } \\
(\mathrm{n}=56)\end{array}$ & $\begin{array}{c}P \\
\text { value }\end{array}$ \\
\hline Major adverse coronary event & $41(9.2)$ & $5(3.9)$ & $12(9.2)$ & $0(0)$ & $18(20.7)$ & $6(10.7)$ & $<.001$ \\
\hline In-hospital mortality & $20(4.5)$ & $2(1.6)$ & $7(5.3)$ & $0(0)$ & $6(6.9)$ & $5(8.9)$ & .071 \\
\hline Cardiac arrest & $14(3.1)$ & $1(0.8)$ & $2(1.5)$ & $0(0)$ & $8(9.2)$ & $3(5.4)$ & .003 \\
\hline Mechanical circulatory support & $25(5.6)$ & $4(3.1)$ & $7(5.3)$ & $0(0)$ & $11(12.6)$ & $3(5.4)$ & .015 \\
\hline Postoperative length of stay (d) & $6.0(4.0-10.0)$ & $4.0(4.0-6.0)$ & $6.0(4.0-10.0)$ & $6.0(4.0-10.0)$ & $8.0(5.0-18.0)$ & $7.0(4.0-11.0)$ & $<.001$ \\
\hline Any postoperative complication & $188(42.1)$ & $33(25.6)$ & $59(45.0)$ & $16(36.4)$ & $51(58.6)$ & $29(51.8)$ & $<.001$ \\
\hline Arrhythmia & $32(7.2)$ & $6(4.7)$ & $13(9.9)$ & $5(11.4)$ & $6(6.9)$ & $2(3.6)$ & .289 \\
\hline $\begin{array}{l}\text { Neurologic deficit (persisting at } \\
\text { discharge) }\end{array}$ & $6(1.3)$ & $2(1.6)$ & $1(0.8)$ & $0(0)$ & $3(3.4)$ & $0(0)$ & .327 \\
\hline Unplanned reoperation & $22(4.9)$ & $3(2.3)$ & $9(6.9)$ & $1(2.3)$ & $7(8.0)$ & $2(3.6)$ & $.2 ?$ \\
\hline Sternum left open & $47(10.5)$ & $6(4.7)$ & $10(7.6)$ & $7(15.9)$ & $20(23.0)$ & $4(7.1)$ & $<.00$ \\
\hline $\begin{array}{l}\text { Prolonged mechanical ventilator } \\
\text { support }\end{array}$ & $15(3.4)$ & $4(3.1)$ & $2(1.5)$ & $3(6.8)$ & $4(4.6)$ & $2(3.6)$ & .49 \\
\hline
\end{tabular}

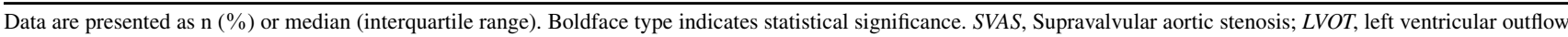
tract; RVOT, right ventricular outflow tract.

(25\%). Preoperative mechanical ventilatory support was the most common (26 out of 447 [6\%]). Preoperative mechanical circulatory support was reported in $1.3 \%$ (6 out of 447). Preoperative risk factors were more frequent in patients undergoing isolated RVOT procedures $(P=.005)$, with the most common risk factors in that group being labeled as other risk factor ( 9 out of 44 [21\%]), mechanical ventilator support (3 out of $44[7 \%]$ ), and neurologic deficit (3 out of $44[7 \%]$ ). Unplanned reoperations were performed in 22 out of 447 patients $(4.9 \%)$.

\section{Outcomes and Risk Factors}

Overall in-hospital mortality in the cohort was 20 out of $447(5 \%)$ (Table 2). Mortality was higher in patients undergoing combined LVOT/RVOT procedures (6 out of 87 $[7 \%]$ ), whereas there were no mortalities in the group of patients undergoing isolated RVOT procedures (Figure 2). There was no significant difference in in-hospital mortality between combined LVOT/RVOT procedures and complex LVOT or isolated SVAS repairs $(P=.07$ and $P=.54$,

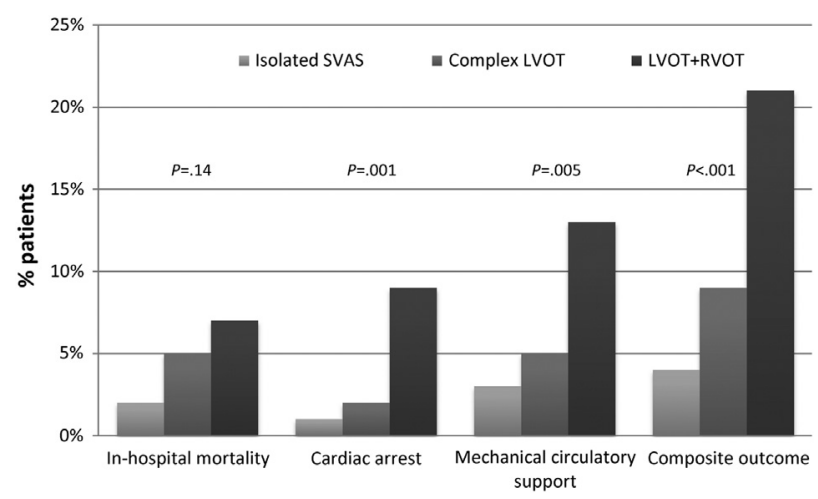

FIGURE 2. Major adverse cardiac events by cardiac surgical procedure group. SVAS, Supravalvular aortic stenosis; LVOT, left ventricular outflow tract; $R V O T$, right ventricular outflow tract. respectively). Postoperative complications were common, occurring in 188 out of 447 cases $(42 \%)$. The most common postoperative complications included sternum left open and arrhythmias (47 out of 447 [11\%] and 32 out of 447 [7\%], respectively).

Overall, MACE occurred after 41 out of 447 procedures (9\%), including 20 deaths, 25 episodes of postoperative mechanical circulatory support (11 out of 25 [44\%] with mortality), and 14 postoperative cardiac arrests (4 out of 14 [29\%] with mortality). MACE were significantly more common after combined LVOT/RVOT (18 out of 87 [21\%]) procedures than after complex LVOT or isolated SVAS procedures $(P<.001$ and $P=.01$, respectively). There were no MACE reported after isolated RVOT procedures. MACE occurred most frequently following procedures involving coronary artery repair either as primary or concomitant procedure (7 out of $22[32 \%]$ ), and in patients with preoperative arrhythmias ( 3 out of 15 [20\%]). Median aortic crossclamp times were longer in patients with MACE compared with those without (86.5 minutes [interquartile range, 59-139 minutes] vs 61 minutes [interquartile range, 41-92 minutes]; $P=.004$ ). This difference was driven by the longer crossclamp time in patients who experienced MACE after isolated SVAS repair (median, 101 minutes [interquartile range, 61-151 minutes] vs 55 minutes [interquartile range, 43-77 minutes]; $P=.03$ ). Aortic crossclamp times did not differ between patients with and without MACE undergoing any other procedure.

The unadjusted odds of MACE were lower with increasing age and weight at surgery (odds ratio [OR], 0.99 per year of age; $95 \%$ confidence interval [CI], 0.98 0.99; and OR, 0.97 per kg; 95\% CI, 0.93-0.99). These effects were seen in isolated SVAS repairs but not in LVOT or combined LVOT/RVOT procedures (Table 3). The presence of any preoperative risk factor was associated with increased odds of MACE (OR, 2.08; 95\% CI, 1.06-4.00). 
TABLE 3. Unadjusted odds ratios $(95 \%$ confidence interval) of major cardiac adverse event

\begin{tabular}{|c|c|c|c|c|c|}
\hline Effect & $\begin{array}{c}\text { Overall } \\
(\mathrm{N}=447)\end{array}$ & $\begin{array}{c}\text { Isolated } \\
\text { SVAS }(n=129)\end{array}$ & $\begin{array}{c}\text { Complex } \\
\text { LVOT }(n=131)\end{array}$ & $\begin{array}{l}\text { LVOT/RVOT } \\
(\mathbf{n}=\mathbf{8 7})\end{array}$ & $\begin{array}{c}\text { Other } \\
(n=56)\end{array}$ \\
\hline \multicolumn{6}{|l|}{ Demographic characteristic } \\
\hline Age at surgery (mo) & $0.99(0.98-0.99)$ & $0.97(0.92-1.00)$ & $1.00(0.99-1.01)$ & $1.00(1.0-1.01)$ & $0.96(0.88-0.99)$ \\
\hline Weight at surgery $(\mathrm{kg})$ & $0.97(0.93-0.99)$ & $0.82(0.63-0.99)$ & $1.00(0.96-1.03)$ & $1.01(0.96-1.05)$ & $0.81(0.59-0.96)$ \\
\hline Female gender & $1.07(0.56-2.03)$ & $2.45(0.46-15.16)$ & $0.66(0.18-2.11)$ & $1.03(0.34-2.94)$ & $2.27(0.41-23.35)$ \\
\hline \multicolumn{6}{|l|}{ Other preoperative factor } \\
\hline Any preoperative risk factors & $2.08(1.06-4.00)$ & $1.61(0.16-9.26)$ & $3.07(0.94-10.06)$ & $1.56(0.46-4.78)$ & $5.54(1.09-35.20)$ \\
\hline Previous cardiac surgery & $0.69(0.26-1.54)$ & $2.44(0.02-28.02)$ & $0.97(0.27-3.11)$ & $0.86(0.15-3.37)$ & $0.12(0.00-1.15)$ \\
\hline
\end{tabular}

Boldface type indicates statistically significant odds ratios. SVAS, Supravalvular aortic stenosis; LVOT, left ventricular outflow tract; RVOT, right ventricular outflow tract.

Gender, race, presence of preoperative arrhythmias, and a history of prior cardiac surgery were not associated with odds of MACE. Procedures involving coronary artery repair had higher unadjusted odds of MACE (OR, 5.37; 95\% CI, 2.05-14.06), whereas the presence of a postoperative arrhythmia was not associated with higher odds of MACE.

\section{DISCUSSION}

The major finding of our study - which was the largest analysis to date of outcomes in patients with WS undergoing cardiac surgical procedures-was a $9 \%$ overall prevalence of MACE, which ranged from $0 \%$ after isolated RVOT procedures to $21 \%$ after combined LVOT/RVOT procedures.

\section{Distribution of Surgical Procedures}

Most surgical procedures in our cohort involved the LVOT. This finding is consistent with the previously reported experience from the Children's Hospital of Philadelphia, where 33 out of 48 surgical interventions $(69 \%)$ were for SVAS, ${ }^{8}$ and the multicenter 19 -year experience of the Pediatric Cardiac Care Consortium, where 32 out of 48 $(67 \%)$ of all surgical interventions were performed for SVAS or combined SVAS and pulmonary artery stenosis. ${ }^{9}$ Isolated RVOT procedures were the least common procedures in our cohort, perhaps reflecting that only the most severe forms of RVOT obstruction are referred for surgical intervention and the availability of nonsurgical alternative forms of therapy. ${ }^{17}$ The finding that the majority of patients undergoing isolated RVOT were younger than age 1 year is consistent with previous reports and likely reflects the higher severity of obstruction requiring earlier surgical intervention in these patients.

Coronary artery procedures are of particular interest in patients with WS, because coronary ostial stenosis has been proposed as etiologic in the occurrence of sudden death, particularly around the time of anesthetic induction. ${ }^{4}$ Similar to prior studies, coronary artery procedures were uncommon $(5 \%)$ and occurred predominantly in patients with complex LVOT or combined LVOT/RVOT procedures $(77 \%)$. It is possible that some of these patients may have undergone coronary artery procedures in response to an intraoperative complication, and not because of a primary coronary anomaly.

\section{Outcomes}

MACE are common after cardiac surgery in patients with WS, but the risk varies by procedure. Although our overall in-hospital mortality of $5 \%$ is comparable to the mortality reported for surgery-related deaths in the Pediatric Cardiac Care Consortium study ${ }^{8}$ and the report from the Children's Hospital of Philadelphia, ${ }^{9}$ our study is the first to report incidence of MACE following surgical intervention in patients with WS. Given the reported mortality rate and the high morbidity associated with MACE, the risks associated with cardiac surgery in WS are significant. This finding is further emphasized when considering that patients with WS generally undergo surgery beyond the neonatal period, and that our cohort consists only of patients with biventricular circulation. Indeed, among the 35 most common procedures performed in children and recorded in the STS-CHS database during the period from 2008 to 2012, only revision or conversion of a Fontan had a higher mortality $(9 \%)$, and mechanical aortic root replacement was the only procedure with similar mortality in patients with biventricular circulation $(5 \%) .{ }^{18}$ In comparison, mortality in children during the same time period was only $0.4 \%$ following the Ross procedure, only $0.3 \%$ following RVOT procedures, and only $0.2 \%$ following aortic stenosis repair. Overall, this information is critical when discussing risk of surgical interventions with patients with WS and their families.

MACE were most common after combined LVOT/RVOT procedures $(21 \%)$. This finding is consistent with prior reports of higher mortality in patients with WS requiring biventricular outflow tract surgery. ${ }^{9}$ It remains unclear whether risk in these patients is increased because of a more severe, underlying WS-related, vascular disease substrate, or simply because of the greater complexity of simultaneous surgical intervention on both outflow tracts. No MACE occurred after isolated RVOT surgery, possibly reflecting both the reduced surgical complexity and the decreased burden of WS-related CV pathology. It should be noted that patients undergoing isolated RVOT surgery still had a relatively high frequency of postoperative 
complications ( $36 \%$ vs $41 \%$ for all other procedures combined). The absence of MACE in these patients despite a $36 \%$ postoperative complication rate may support the possibility that MACE in patients with WS is related to the underlying WS-related disease substrate and not just the increased surgical complexity associated with left-sided interventions.

\section{Mechanisms of MACE}

The exact mechanism of MACE in patients with WS is unknown. Surgical relief of either SVAS or more distal arch obstruction will substantially decrease coronary perfusion pressure. Because coronary ostial stenosis has previously been implicated as a potential explanation for cardiac arrest in patients with WS, we postulated that MACE would be more common after these left-sided cardiac surgeries. ${ }^{4,6}$ However, MACE was significantly less frequent in our cohort after isolated SVAS repair when compared with other left-sided cardiac surgeries, suggesting that the mechanisms may be more complex. Similar to several smaller studies, we found that bilateral outflow tract obstruction and coronary ostial stenoses were both risk factors. However in our analysis and in others, MACE occurred in the absence of both findings. ${ }^{89}$ Arrhythmias may play an important role, because prolongation of the QTc interval has been found in a subset of patients with WS. ${ }^{5}$ This may be related to myocardial ischemia, as QTc interval prolongation has also been correlated with the occurrence of ventricular ectopy. ${ }^{19}$ Although MACE occurred more frequently in patients with preoperative arrhythmias, the unadjusted odds of MACE were not significantly different in these patients. Known surgical risk factors such as lower age and weight at surgery, the presence of any preoperative complication, and longer aortic crossclamp time were associated with increased odds of MACE. As a whole, the increased risk of MACE in patients with WS may be mediated by several different factors, including the need for surgical intervention at younger age and lower weight in the most severely affected patients; coronary artery anomalies requiring intervention, seen more frequently in combined LVOT/RVOT procedures and complex LVOT procedures; and unforeseen intraoperative complications requiring longer aortic crossclamp times even in overall lower risk groups such as isolated SVAS repair.

The strengths of our study include its sample size and data source. The STS-CHS database captures the majority of congenital heart surgeries performed in the United States. The detailed data collection allowed us to separate patients by type of surgery performed, and uncovered differences between types of LVOT procedures, combined LVOT/RVOT procedures, and cases with concomitant coronary artery interventions. The knowledge of postoperative complications, including cardiac arrest and need for mechanical circulatory support, allowed us to identify the meaningful and much more common outcome of MACE, rather than focusing on postoperative mortality alone. Although the overall incidence of MACE was high, the population was heterogeneous with respect to surgical procedures and risk factors, and the number of events by subgroups was limited. Despite the wealth of data collected in the STS-CHS database, details of individual cases, including unusual intraoperative findings that may be common in this population, are not available. Further, at the time of our analysis, details of the anesthetic management, postulated to play a significant role in MACE in patients with WS, were not reliably captured in the database and therefore could not be included in this analysis. Finally, additional measures of postcardiotomy cardiovascular compromise such as intermittent episodes of ischemia or prolonged need for inotropic support were not available in the database and could therefore not be evaluated in the analysis. Taken together, these limitations would have diminished the interpretability of a multivariable analysis, and for these reasons we elected a primarily descriptive focus for this study.

\section{CONCLUSIONS}

We found a $9 \%$ incidence of MACE after surgical intervention in patients with WS, highlighting the significant risk associated with certain operations in these patients. Although the exact mechanism of MACE is difficult to elucidate in a retrospective, database-driven study, our findings suggest a multifactorial etiology of this outcome in the WS population.

\section{Conflict of Interest Statement}

Authors have nothing to disclose with regard to commercial support.

\section{References}

1. Pober BR. Williams-Beuren syndrome. N Engl J Med. 2010;362:239-52.

2. Collins RT 2nd. Cardiovascular disease in Williams syndrome. Circulation. 2013;127:2125-34.

3. Collins RT 2nd, Kaplan P, Somes GW, Rome JJ. Cardiovascular abnormalities, interventions, and long-term outcomes in infantile Williams syndrome. J Pediatr. 2010;156:253-8.e1.

4. Bird LM, Billman GF, Lacro RV, Spicer RL, Jariwala LK, Hoyme HE, et al. Sudden death in Williams syndrome: report of ten cases. J Pediatr. 1996;129:926-31.

5. Collins RT 2nd. Clinical significance of prolonged QTc interval in Williams syndrome. Am J Cardiol. 2011;108:471-3.

6. Burch TM, McGowan FX Jr, Kussman BD, Powell AJ, DiNardo JA. Congenital supravalvular aortic stenosis and sudden death associated with anesthesia: what's the mystery? Anesth Analg. 2008;107:1848-54.

7. Collins RT 2nd, Aziz PF, Gleason MM, Kaplan PB, Shah MJ. Abnormalities of cardiac repolarization in Williams syndrome. Am J Cardiol. 2010;106:1029-33.

8. Collins RT 2nd, Kaplan P, Somes GW, Rome JJ. Long-term outcomes of patients with cardiovascular abnormalities and Williams syndrome. Am J Cardiol. 2010; 105:874-8.

9. Pham PP, Moller JH, Hills C, Larson V, Pyles L. Cardiac catheterization and operative outcomes from a multicenter consortium for children with Williams syndrome. Pediatr Cardiol. 2009;30:9-14.

10. Jacobs ML, Mavroudis C, Jacobs JP, Tchervenkov CI, Pelletier GJ. Report of the 2005 STS Congenital Heart Surgery Practice and Manpower Survey. Ann Thorac Surg. 2006;82:1152-8. 9e1-5.

11. Franklin RC, Jacobs JP, Krogmann ON, Beland MJ, Aiello VD, Colan SD, et al Nomenclature for congenital and paediatric cardiac disease: historical perspectives and The International Pediatric and Congenital Cardiac Code. Cardiol Young. 2008;18(Suppl 2):70-80. 
12. STS Congenital Heart Surgery Database v3.0. Available at: http:/www.sts.org/ sites/defaultfiles/pdf/congenitaldataspecficationsV3_0_20090904.pdf. Accessed December 30, 2013.

13. Clarke DR, Breen LS, Jacobs ML, Franklin RC, Tobota Z, Maruszewski B, et al. Verification of data in congenital cardiac surgery. Cardiol Young. 2008;18(Suppl 2):177-87.

14. Society of Thoracic Surgeons. Society of Thoracic Surgeons National Database. Available at: http://www.sts.org/sections/stsnationaldatabase/. Accessed August 1,2014

15. Society of Thoracic Surgeons. STS Congenital Heart Surgery Database. Data collection. Available at: http://www.sts.org/node/518. Accessed August 1, 2014.

16. Hawn MT, Graham LA, Richman JS, Itani KM, Henderson WG, Maddox TM Risk of major adverse cardiac events following noncardiac surgery in patients with coronary stents. JAMA. 2013;310:1462-72.
17. Del Pasqua A, Rinelli G, Toscano A, Iacobelli R, Digilio C, Marino B, et al. New findings concerning cardiovascular manifestations emerging from long-term follow-up of 150 patients with the Williams-Beuren-Beuren syndrome. Cardiol Young. 2009;19:563-7.

18. Jacobs JP, Jacobs ML, Mavroudis C, Lacour-Gayet FG, Tchervenkov CI. Executive summary: the Society of Thoracic Surgeons Congenital Heart Surgery Database - seventeenth harvest - (July 1, 2008 - June 30, 2012). Available at: www.sts.org. Accessed August 1, 2014.

19. Collins RT 2nd, Aziz PF, Swearingen CJ, Kaplan PB. Relation of ventricular ectopic complexes to QTc interval on ambulatory electrocardiograms in Williams syndrome. Am J Cardiol. 2012;109:1671-6.

Key Words: Williams syndrome, major adverse cardiac events, risk factors

\title{
EDITORIAL COMMENTARY
}

\section{Does chance truly favor the prepared mind?}

\author{
Jonathan M. Chen, MD
}

See related article on pages 1516-22.

As mortality statistics for complex congenital heart surgery drift asymptotically toward zero, significant perioperative morbidities have taken a more prominent position as a target of focus for quality improvement. Indeed, the long-term consequences of a perioperative major adverse cardiac event (MACE) can sully a sense of triumph with a technically excellent repair, and heightened awareness of "bad actors" among the dramatis personae may help to identify those at risk and thereby reduce the failureto-rescue rate. In this issue of the Journal, Hornik and colleagues ${ }^{1}$ present an observational study of the Society of Thoracic Surgeons database, which contains the largest cohort to date of patients with Williams-Bueren syndrome undergoing cardiovascular surgery. Their results (that the

From Pediatric Cardiovascular Surgery, Seattle Children's Hospital, and the Division of Cardiothoracic Surgery, University of Washington School of Medicine, Seattle, Wash.

Disclosures: Author has nothing to disclose with regard to commercial support.

Received for publication Feb 23, 2015; accepted for publication Feb 25, 2015; available ahead of print March 24, 2015.

Address for reprints: Jonathan M. Chen, MD, Department of Cardiothoracic Surgery, Seattle Children's Hospital, 4800 Sand Point Way NE-RC 2.820, Seattle, WA 98105 (E-mail: jmchen@uw.edu).

J Thorac Cardiovasc Surg 2015;149:1522-3

$0022-5223 / \$ 36.00$

Copyright (c) 2015 by The American Association for Thoracic Surgery

http://dx.doi.org/10.1016/j.jtcvs.2015.02.053 entire cohort had a MACE incidence of $9 \%$, whereas those with combined left ventricular outflow tract (LVOT) and right ventricular outflow tract (RVOT) repair had a MACE incidence of $21 \%$ ) apply sobering statistics to what perhaps has been an assumed truth among congenital surgeons; namely, that from initial anesthetic induction to

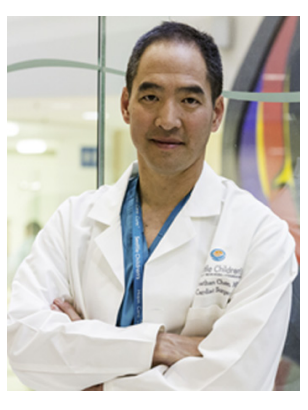
ultimate hospital discharge, children with Williams syndrome are at high risk for an adverse cardiac event.

These demographic data demonstrate an overall mortality of $5 \%$ but a range of MACE outcomes, depending upon the type of procedure performed (isolated RVOT, $0 \%$; complex LVOT, 9\%; and combined LVOT and RVOT, $21 \%$ ), age, the presence of other preoperative risk factors, and the need for coronary artery repair. As a large retrospective database study, more subtle cardiac morbidities were not discernable for better characterization of these events (eg, inotrope score, evidence of ischemia). Moreover, 46 of the patients $(9 \%)$ were excluded because of missing information regarding postoperative complications, and it is not possible to determine from the Society of Thoracic Surgeons database whether the coronary interventions were due to intraoperative complications or primary coronary anatomy.

These shortcomings become so pronounced, however, largely because the compelling nature of the data leaves 
TABLE E1. Surgical procedures

\begin{tabular}{|c|c|c|c|c|c|c|}
\hline Primary procedure & $\begin{array}{c}\text { Overall } \\
(N=447)\end{array}$ & $\begin{array}{l}\text { Isolated SVAS } \\
\quad(\mathbf{n}=\mathbf{1 2 9})\end{array}$ & $\begin{array}{l}\text { Complex LVOT } \\
\quad(\mathbf{n}=\mathbf{1 3 1})\end{array}$ & $\begin{array}{l}\text { Isolated RVOT } \\
\quad(n=44)\end{array}$ & $\begin{array}{l}\text { LVOT/RVOT } \\
\quad(\mathbf{n}=\mathbf{8 7})\end{array}$ & $\begin{array}{c}\text { Other } \\
(\mathbf{n}=\mathbf{5 6})\end{array}$ \\
\hline $\begin{array}{l}\text { Aortic stenosis, supravalvular, } \\
\text { repair }\end{array}$ & $181(40.5)$ & $129(100.0)$ & $24(18.3)$ & $0(0.0)$ & $28(32.2)$ & $0(0.0)$ \\
\hline Aortic arch repair & $53(11.9)$ & $0(0.0)$ & $39(29.8)$ & $0(0.0)$ & $14(16.1)$ & $0(0.0)$ \\
\hline $\begin{array}{l}\text { Coarctation repair, patch } \\
\text { aortoplasty }\end{array}$ & $11(2.5)$ & $0(0.0)$ & $11(8.4)$ & $0(0.0)$ & $0(0.0)$ & $0(0.0)$ \\
\hline Valvuloplasty, aortic & $12(2.7)$ & $0(0.0)$ & $9(6.9)$ & $0(0.0)$ & $3(3.4)$ & $0(0.0)$ \\
\hline Coarctation repair, end to end & $6(1.3)$ & $0(0.0)$ & $6(4.6)$ & $0(0.0)$ & $0(0.0)$ & $0(0.0)$ \\
\hline $\begin{array}{l}\text { Coarctation repair, end to end, } \\
\text { extended }\end{array}$ & $5(1.1)$ & $0(0.0)$ & $5(3.8)$ & $0(0.0)$ & $0(0.0)$ & $0(0.0)$ \\
\hline Aortic aneurysm repair & $5(1.1)$ & $0(0.0)$ & $5(3.8)$ & $0(0.0)$ & $0(0.0)$ & $0(0.0)$ \\
\hline Valvuloplasty, mitral & $17(3.8)$ & $0(0.0)$ & $2(1.5)$ & $0(0.0)$ & $1(1.1)$ & $14(25.0)$ \\
\hline $\begin{array}{l}\text { Pulmonary artery, } \\
\text { reconstruction, branch, } \\
\text { central (within the hilar } \\
\text { bifurcation) }\end{array}$ & $48(10.7)$ & $0(0.0)$ & $0(0.0)$ & $15(34.1)$ & $33(37.9)$ & $0(0.0)$ \\
\hline RVOT procedure & $10(2.2)$ & $0(0.0)$ & $0(0.0)$ & $10(22.7)$ & $0(0.0)$ & $0(0.0)$ \\
\hline $\begin{array}{l}\text { Pulmonary artery, } \\
\text { reconstruction, main } \\
\text { (trunk) }\end{array}$ & $7(1.6)$ & $0(0.0)$ & $0(0.0)$ & $7(15.9)$ & $0(0.0)$ & $0(0.0)$ \\
\hline $\begin{array}{l}\text { Pulmonary artery, } \\
\text { reconstruction, branch (at } \\
\text { or beyond the hilar } \\
\text { bifurcation) }\end{array}$ & $6(1.3)$ & $0(0.0)$ & $0(0.0)$ & $3(6.8)$ & $3(3.4)$ & $0(0.0)$ \\
\hline $\begin{array}{l}\text { Ventricular septal defect } \\
\text { repair, patch }\end{array}$ & $5(1.1)$ & $0(0.0)$ & $0(0.0)$ & $1(2.3)$ & $0(0.0)$ & $4(7.1)$ \\
\hline
\end{tabular}

